\title{
THE PROTON FLARE OF AUGUST 28, 1966*
}

\author{
HELEN W. DODSON and E. RUTH HEDEMAN \\ McMath-Hulbert Observatory, The University of Michigan, Ann Arbor, Mich., U.S.A.
}

(Received 27 December, 1967)

\begin{abstract}
The proton flare of August 28, 1966 began on $\mathrm{H} \alpha$ records at $15^{\mathrm{h}} 21^{\mathrm{m}} 35^{\mathrm{s}}$ UT. It presented an unusually complex development with flare emission occurring in two distinct plages. The brightest part of the flare attained maximum intensity, $152 \%$ of the continuum, between $15^{\mathrm{h}} 30^{\mathrm{m}}$ and $15^{\mathrm{h}} 32^{\mathrm{m}}$ UT. Photometric measurements show that a long-enduring part of the flare continued to decline in intensity until at least $21^{\mathrm{h}} 20^{\mathrm{m}} \mathrm{UT}$.

The flare developed first in parts of the plages that were near the extremities of a filament and a complex system of curvilinear absorption structures, possibly an eruptive prominence in projection. During the rise to maximum intensity a large expanding feature moved southward from the site of the flare with a velocity $\sim 700 \mathrm{~km} / \mathrm{sec}$. Its appearance on monochromatic records of the chromosphere made in the center of $\mathrm{H} \alpha$ and $0.5 \AA$ on either side was consistent with the effect of an advancing phenomenon that induces a small shift of the $\mathrm{H} \alpha$ absorption line, first to longer, and then to shorter wavelengths.

Two bright flare-filaments were obvious aspects of the event by $15^{\mathrm{h}} 28^{\mathrm{m}}$ and dominated the main phase of the flare. Loop-type prominences were observed in absorption as early as $15^{\mathrm{h}} 40^{\mathrm{m}}$.
\end{abstract}

\section{General Description of Outbreak and Development of the Ha Flare}

The proton flare of August 28, 1966 (Imp. 2B or greater, N22 E05) occurred in two well-defined plages, each with separate spot groups, and presented an unusually complex development. The first evidence of flare-emission on the $\mathrm{H} \alpha$ patrol films of the McMath-Hulbert Observatory $\left(0.5 \AA\right.$ band pass) occurred at $15^{\mathrm{h}} 21^{\mathrm{m}} 35^{\mathrm{s}} \mathrm{UT}^{* *}$ when a small area, region 1 in Figure 1A, on the North side of filament F (Figure 1B) suddenly increased in intensity. Thirty seconds later another small point, region 2, directly across the filament and on the South side was also the site of flare-emission. These two initial brightenings were in the plage surrounding the dying $\beta$ spot group (Mt. Wilson No. 16111) that preceded by approximately $15^{\circ}$ the large $\beta \gamma$ spot (Mt. Wilson No. 16114) near which the principal $\mathrm{H} \alpha$ emission of this proton flare would occur. By $15^{\mathrm{h}} 22^{\mathrm{m}} 35^{\mathrm{s}}$ flare-emission had started at regions 3 and 4 within the large bright plage surrounding the $\beta \gamma$ spot. The flare then broke out in numerous small bright points, some of which are indicated in Figure 1. Intensity increased rapidly at $15^{\mathrm{h}} 24^{\mathrm{m}}$ and $15^{\mathrm{h}} 25^{\mathrm{m}} \mathrm{UT}$ and maximum intensity was reached between $15^{\mathrm{h}} 30^{\mathrm{m}}$ and $15^{\mathrm{h}} 32^{\mathrm{m}} \mathrm{UT}$. (See Figure 2.)

The regions of enhanced emission for this flare fall naturally into two parts, the

* This investigation was supported in part by the Office of Naval Research through funds from Nonr-1224(19), and in part by the National Science Foundation through funds from GA-632.

** It should be remembered that 'starting times' on monochromatic records can be in error because of the effects of Doppler displacements. Available data suggest that such effects are small for flares near the center of the solar disk. 


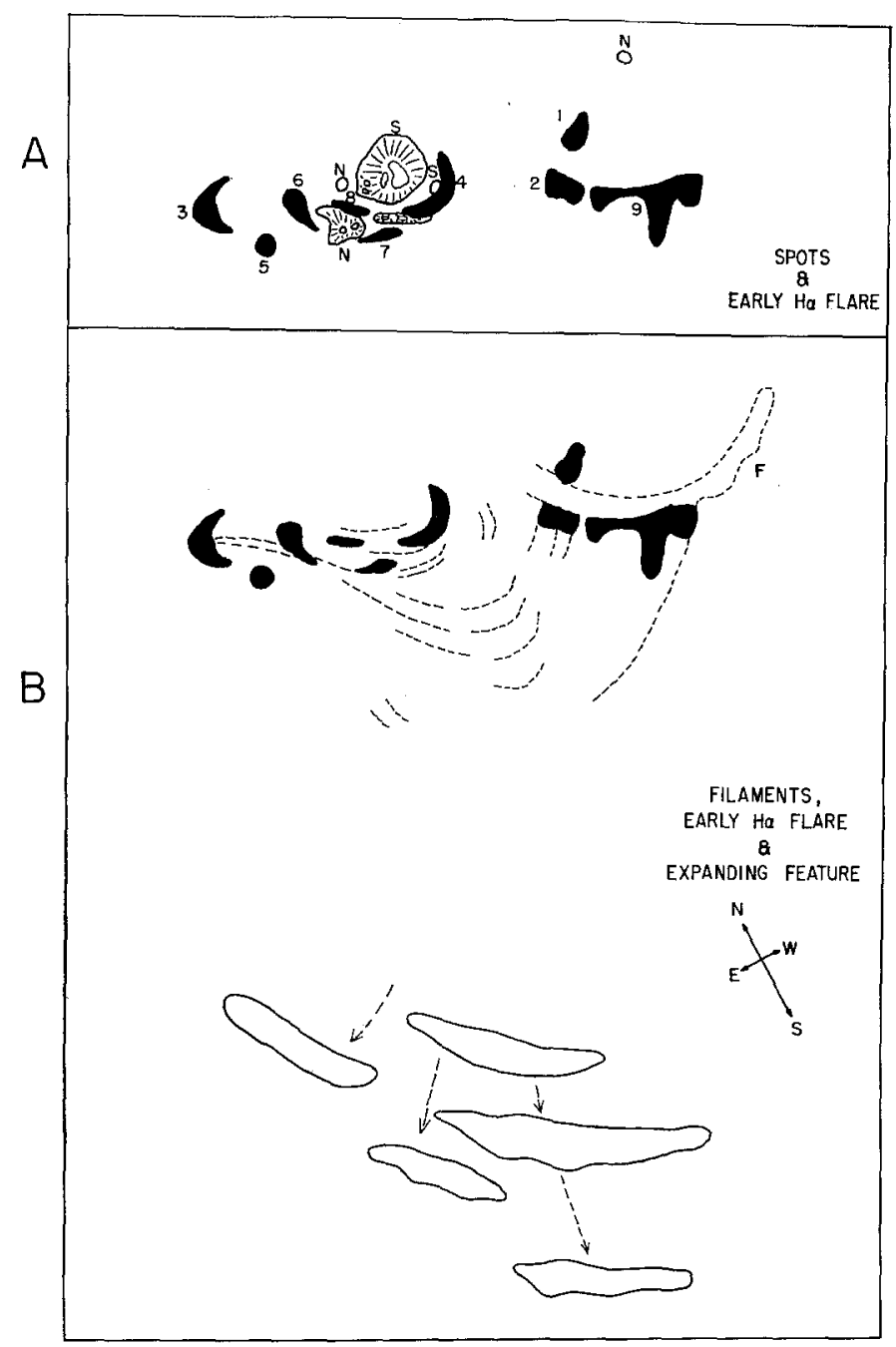

Fig. 1. Location of bright $\mathrm{H} \alpha$ emission during the early development of the flare, Imp. $>2$, August 28, 1966. (A) Position of flare with respect to spots. Flare emission is shown by black areas. Adjacent numbers indicate the order in which the respective regions became visible. The letters $\mathbf{N}$ and S refer to the polarity of the spots. (B) Position of flare with respect to filaments and absorption features (shown by dotted lines). The arcs in the Southern part of the field indicate successive locations of the rapidly expanding feature.

first in the preceding or Western plage and the second in the following or Eastern plage. Parts I and II were markedly different in character. Although it can be argued that the two parts should be treated as separate flares, the development and morphology of the flare-emission support the idea that the two parts refer to a single physical event. They illustrate the rather rare occurrence of a flare in more than one plage and 
emphasize anew that single plages often prove too small for the concept of a 'center of activity' (Dodson and Hedeman, 1967).

Part I of the August 28 proton flare consisted primarily of flare-emission on the borders and to the South of filament F. It was in Part I that the flare began. The spot group in the associated plage had been decreasing rapidly in area and complexity in the three preceding days.

Part II included the brightest parts of the flare, the two bright filaments so characteristic of proton flares, and the region of long-lasting emission that prolonged the

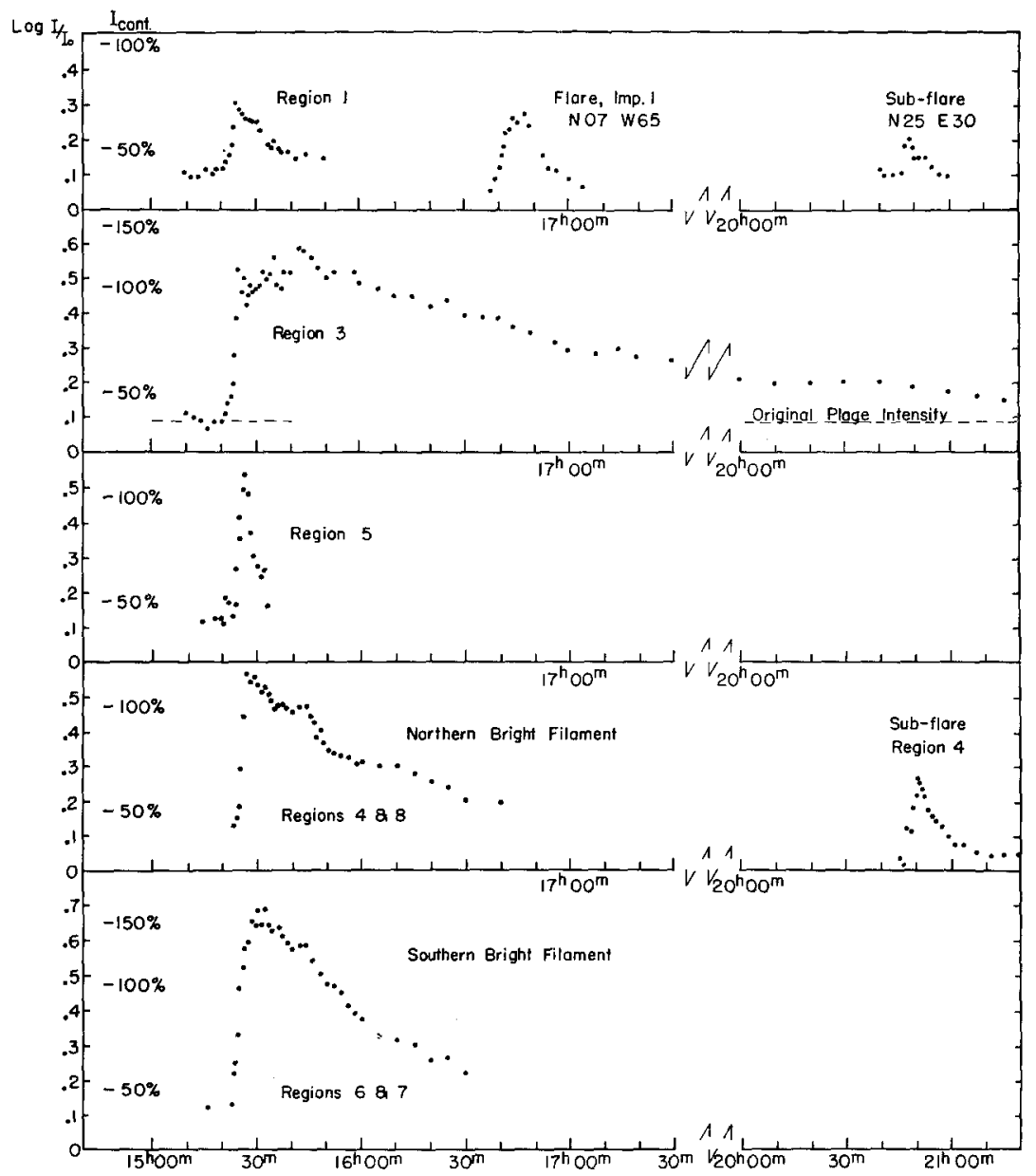

Fig. 2. Photometric light curves for specific regions within the flare, Imp. $>2$, August 28, 1966. $\log I / I_{0}$ gives the logarithum of the intensity of the $\mathrm{H} \alpha$ flare in units of the undisturbed $\mathrm{H} \alpha$ background at the center of the solar disk. $I_{\text {cont }}$ gives the intensity of the $\mathrm{H} \alpha$ flare in percent of the intensity of the continuous spectrum near $\mathbf{H} \alpha$ and at the center of the solar disk. The locations of the regions can be identified in Figure 1A. Light curves for a flare and a subflare at other locations on the solar disk are also included in the first strip of the diagram. 
flare until at least $21^{\mathrm{h}} 20^{\mathrm{m}}$ UT. The associated spot group had been increasing in area and complexity for the past three days. It is of interest to note that this spot, at latitude $\mathrm{N} 24^{\circ}$, was colongitudinal, at Carrington longitude $\sim 180^{\circ}$, with the remnant of the spot group at $\mathrm{N} 35^{\circ}$, in which the proton flare of July 7, 1966 had occurred. In early July the two regions had been separated by $27^{\circ}$ of longitude. Differential rotation had made the two spot groups colongitudinal by August 28 .

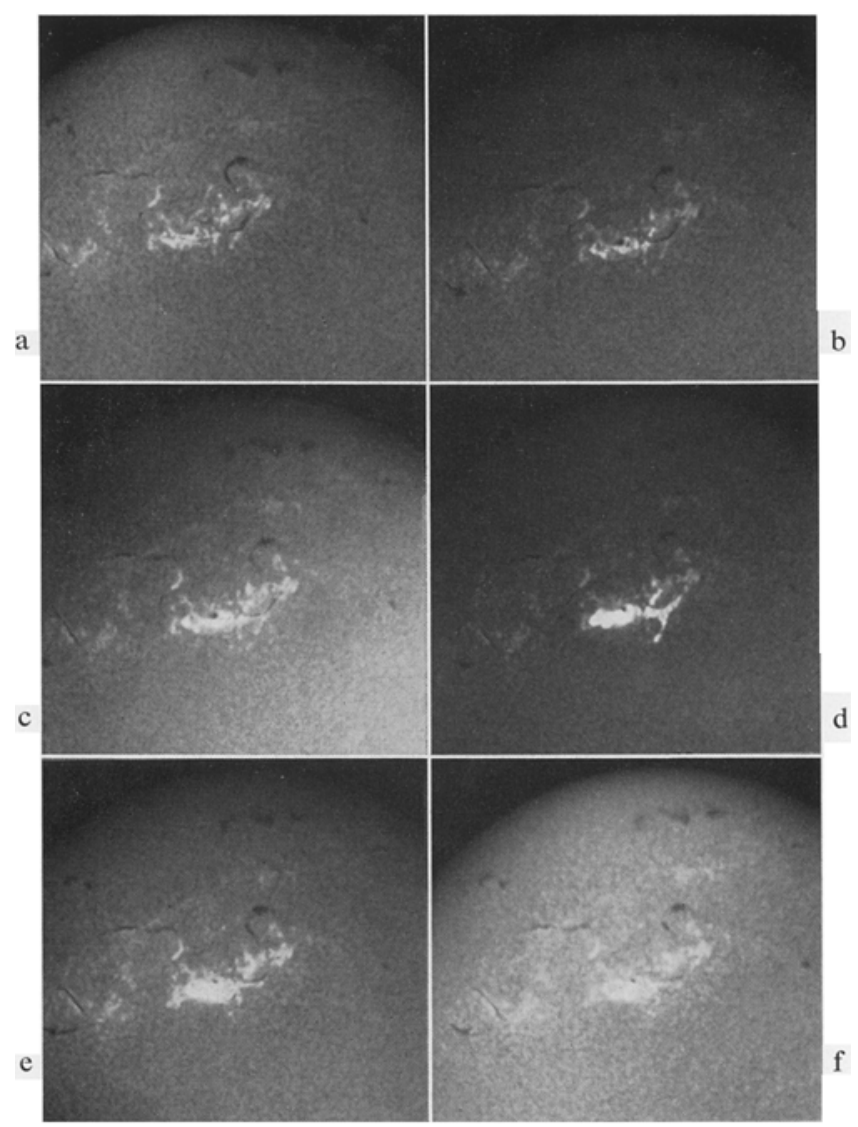

Fig. 3. H $\alpha$ filtroheliograms showing the site and development of the flare, Imp. $>2$, August 28, 1966. (a) $13^{\mathrm{h}} 26^{\mathrm{m}} \mathrm{UT}$, before flare; (b) $15^{\mathrm{h}} 21^{\mathrm{m}} 35^{\mathrm{s}}$, start of flare; (c) $15^{\mathrm{h}} 24^{\mathrm{m}} 05^{\mathrm{s}}$, start of rapid increase in intensity; (d) $15^{\mathrm{h}} 27^{\mathrm{m}} 35^{\mathrm{s}}$, approaching maximum intensity; (c) $16^{\mathrm{h}} 00^{\mathrm{m}}$, post maximum phase; and (f) $17^{\mathrm{h}} 00^{\mathrm{m}}$, late in flare.

The double bright filaments that dominated the major phase of the flare on August 28 were not visible structures during the first 4 minutes of the flare. They began to appear as 'filaments' at $15^{\mathrm{h}} 26^{\mathrm{m}} \mathrm{UT}$, and by $15^{\mathrm{h}} 28^{\mathrm{m}}$ formed the brightest part of the flare. The two filaments were not the result of the splitting of a single filament. They grew through a melding of numerous small bright dots or regions that stretched out into 
little lines. The Southern branch of the double filament formed primarily from the coalescence of regions 6 and 7, and the Northern branch from a joining of regions 4 and 8 . The bright filaments appeared to move apart with the passage of time. Both branches shared in the apparent motion. The small scale of the pictures does not permit distinction between actual motion of the bright filaments and successive brightening of adjacent features.

Spectroheliograms made with radiation from the wings of $\mathrm{H} \alpha$ show that as early as $15^{\mathrm{h}} 40^{\mathrm{m}} \mathrm{UT}$ absorption features with + Doppler shifts were visible on the inner boundaries of the two bright flare-filaments. We attribute these dark features to the occurrence of a system of loop-type prominences. This phenomenon was conspicuous at $16^{\mathrm{h}} 00^{\mathrm{m}} \mathrm{UT}$ and was still detectable at $17^{\mathrm{h}} 25^{\mathrm{m}} \mathrm{UT}$.

On the basis of simple examination of the filtroheliograms we reported the flare as having ended at $20^{\mathrm{h}} 00^{\mathrm{m}}$ UT. Photometric measurements show that the previously flaring regions continued to diminish in intensity until at least $21^{\mathrm{h}} 20^{\mathrm{m}} \mathrm{UT}$. The general development of the $\mathrm{H} \alpha$ flare is illustrated in Figure 3.

\section{Photometric Measurements of the Flare}

The photometric light curves for individual parts of the flare illustrate the complexity of its development. (See Figure 2.) The first region to brighten, region 1, was considered to be a 'flare' at $15^{\mathrm{h}} 21^{\mathrm{m}} 35^{\mathrm{s}}$, but the film and photometric measurements show that this region underwent a small intensity increase as early as $15^{\mathrm{h}} 17^{\mathrm{m}}$. Region 1 did not become as bright as other parts of the flare, nor did it continue at flare-intensity for a long interval of time. On the other hand region 3 , the site of the earliest brightening in the Eastern part of the flare, rose to a high maximum, $130 \%$ of the continuous spectrum at the center of the disk. This region was so closely related spatially to the long enduring bright curved feature of the late phase of the flare that the photometric aspects of these two features are combined in a single light curve.

Regions 3, 5 and the long enduring bright arc all lay on the Northern boundary of a large pool of absorption closely associated with a complex system of curvilinear absorption structures to be described later. The light curve of region 3 reflects the influence of the growth of this absorption. The rapidly increasing intensity of region 3 is interrupted at $15^{\mathrm{h}} 26^{\mathrm{m}} \mathrm{UT}$ by the apparent onset of absorption over the region. The light curve becomes irregular and maximum intensity is not attained until relatively late in the flare, $15^{\mathrm{h}} 42^{\mathrm{m}} \mathrm{UT}$.

Region 5 was a flare-area of special interest. It rose by $15^{\mathrm{h}} 27^{\mathrm{m}}$ UT to an intensity maximum equal to $113 \%$ of the continuous spectrum. Region 5 , like region 3 , then became so influenced by the developing absorption feature that a rapid diminution in intensity was in progress by $15^{\mathrm{h}} 28^{\mathrm{m}} \mathrm{UT}$. As a consequence, this region has an atypical light curve with very sudden decline (Dodson et al., 1956). It has been shown in a previous study (DoDson, 1952), that overlying prominence material can modify significantly the emergent radiation from a flaring center. The flare of August 28, 1966 apparently provided another example of this situation. 
As mentioned earlier the two parallel bright filaments formed the most intense part of the flare. The Southern one was the brighter of the two filaments and reached maximum intensity, $150 \%$ of the continuum, between $15^{\mathrm{h}} 30^{\mathrm{m}} \mathrm{UT}$ and $15^{\mathrm{h}} 32^{\mathrm{m}} \mathrm{UT}$.

The flare of August 28, 1966 illustrates well the problems inherent in assigning a meaningful 'time of maximum' to an event as complicated as a major flare. Table I shows the wide range in times of maximum for selected regions in the flare.

TABLE I

\begin{tabular}{ccc}
\hline Region & $\begin{array}{c}\text { Maximum Intensity in } \\
\% \text { of Continuum }\end{array}$ & $\begin{array}{c}\text { Time of Maximum } \\
\text { UT }\end{array}$ \\
\hline 1 & 68 & $15^{\mathrm{h}} 25^{\mathrm{m}}$ \\
3 & 130 & 1542 \\
5 & 113 & 1527 \\
$\begin{array}{c}\text { Northern bright } \\
\text { filament (4\&8) } \\
\text { Southern bright } \\
\text { filament (6\&7) }\end{array}$ & 121 & 1527 \\
\hline
\end{tabular}

In general, an observer attempts to report the time of maximum of the brightest part of the complex event, in this case $15^{\mathrm{h}} 30^{\mathrm{m}}-15^{\mathrm{h}} 32^{\mathrm{m}} \mathrm{UT}$.

It should be noted that there were several other flaring regions on the solar disk on August 28 in addition to the regions associated with the proton flare. A low latitude, new cycle, long enduring spot group was, on this date, located at $\mathrm{N} 07^{\circ} \mathrm{W} 65^{\circ}$. A welldefined flare of importance 1 took place in this region from $16^{\mathrm{h}} 38^{\mathrm{m}}-17^{\mathrm{h}} 00^{\mathrm{m}} \mathrm{UT}$. Its photometric light curve is shown in the top line of Figure 2. At $20^{\mathrm{h}} 47^{\mathrm{m}} \mathrm{UT}$ a part of region 4 brightened again into a subflare. Concomitantly with this event, there was still another subflare in a third region, $\mathrm{N} 25^{\circ} \mathrm{E} 30^{\circ}$, from $20^{\mathrm{h}} 46-20^{\mathrm{h}} 57^{\mathrm{m}}$ UT. The light curves for these events also are shown in Figure2.

\section{The Rapidly Expanding Feature}

The flare of August 28, 1966 was accompanied by a large rapidly expanding feature which appeared as a bright arc against the background of the undisturbed solar disk in center-of-H $\alpha$ filtroheliograms recorded at Lake Angelus and Sacramento Peak. It was primarily a broad dark feature on filtroheliograms made $\sim 0.5 \AA$ from the center of $\mathrm{H} \alpha$ at the latter observatory. The large structure was curved, concave toward the flare, and moved Southward with an apparent velocity $\sim 700 \mathrm{~km} / \mathrm{sec}$. (See Figures 1B, 4, 5.) Between $15^{\mathrm{h}} 28^{\mathrm{m}}$ and $15^{\mathrm{h}} 36^{\mathrm{m}}$ UT it was a measurable feature and was observed to move from $\sim 203000 \mathrm{~km}$ to $\sim 520000 \mathrm{~km}$ from the center of the flare. At $\sim 15^{\mathrm{h}} 30^{\mathrm{m}}$ the arc was as bright as faint $\mathrm{H} \alpha$ plage and at that time appeared to form, with previously existing and stable plage structures, an almost circular figure surrounding the flare. (See Figure 4.) The brightest portions of the feature are sketched in Figure 1B. 
The large, primarily dark arcs shown on Sacramento Peak filtroheliograms made $0.5 \AA$ on either side of the center of $\mathrm{H} \alpha$ are especially interesting. They are broad and correspond to a zone $>100000 \mathrm{~km}$ wide. At a velocity of $700 \mathrm{~km} / \mathrm{sec}$ this zone would be traversed in 2-3 min. Examination of successive frames in the record shows that specific portions of the solar disk exhibited the absorption feature for 2-3 min. De-
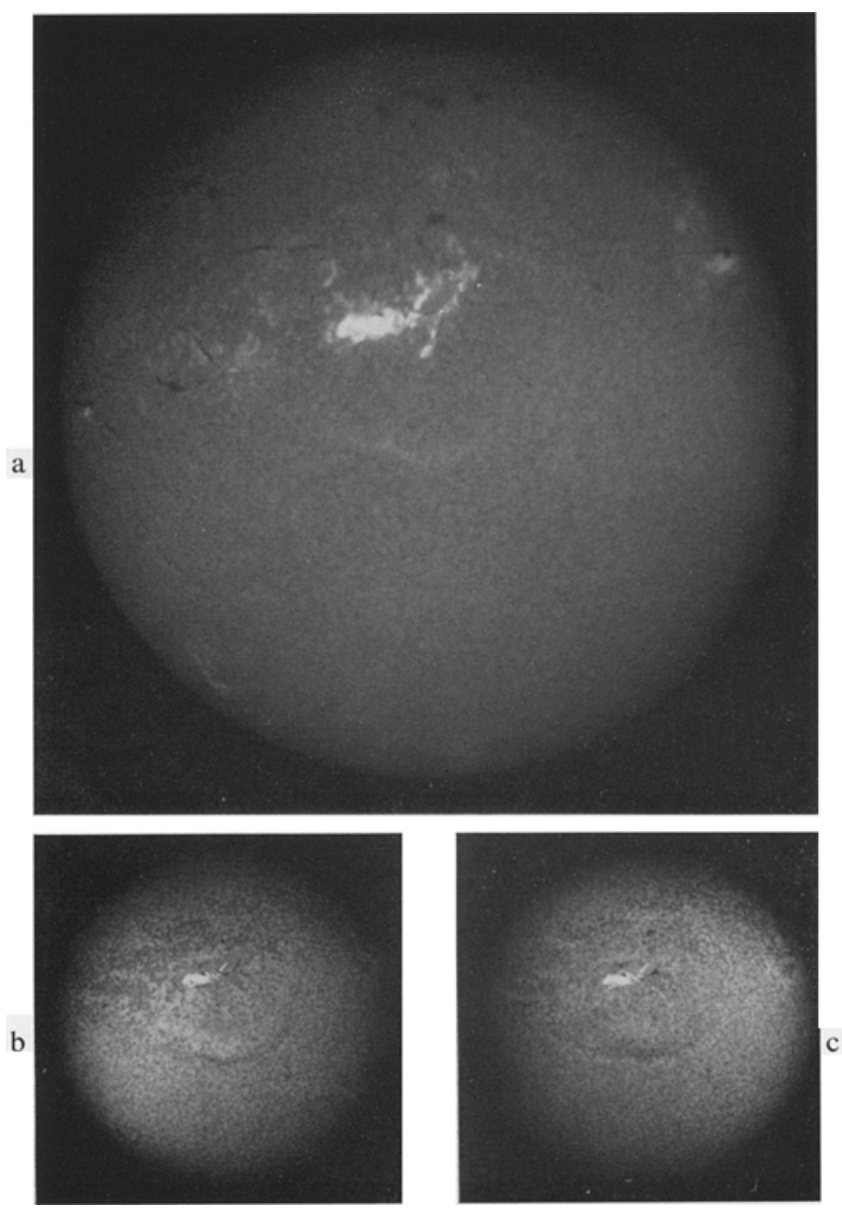

Fig. 4. H $\alpha$ filtroheliograms showing flare, Imp. $>2$, August 28, 1966 at maximum intensity and with rapidly expanding feature. (a) $15^{\mathrm{h}} 29^{\mathrm{m}} 35^{\mathrm{s}} \mathrm{UT}$, Center of $\mathrm{H} \alpha$; (b) $15^{\mathrm{h}} 31^{\mathrm{m}} 35^{\mathrm{s}} \mathrm{UT}, \mathrm{H} \alpha+0.5 \AA$ (Sacramento Peak record); and (c) $15^{\mathrm{h}} 31^{\mathrm{m}} 45^{\mathrm{s}} \mathrm{UT}, \mathrm{H} \alpha-0.5 \AA$ (Sacramento Peak record)

tailed comparison of the filtroheliograms made on the red side of $\mathrm{H} \alpha$ with those secured on the blue side shows that the records are not identical. Pictures made with radiation $0.5 \AA$ to the red side of $\mathrm{H} \alpha$ consistently show a dark arc with a somewhat bright region on the following or inner margin; those made on the blue side of $\mathrm{H} \alpha$ show a dark arc with a bright border on the outer or advancing edge. On filtrohelio- 
grams separated in time by only $10 \mathrm{sec}$, the leading dark absorption arcs of the redward $(+0.5 \AA)$ records coincide in position with the leading bright edges of the blueward $(-0.5 \AA)$ pictures, and the following bright margins of the redward records with the following dark arcs of pictures made on the blue side of $\mathrm{H} \alpha$. These observations can be explained by an advancing phenomenon that induces a small Doppler shift of the $H \alpha$ absorption line first to longer, and then to shorter wavelengths.

The foregoing comments recall the circumstances associated with filament-activation at the time of certain flares. In these cases the dark absorption of the filament is displaced first to the redward, then a small number of minutes later it occurs on the

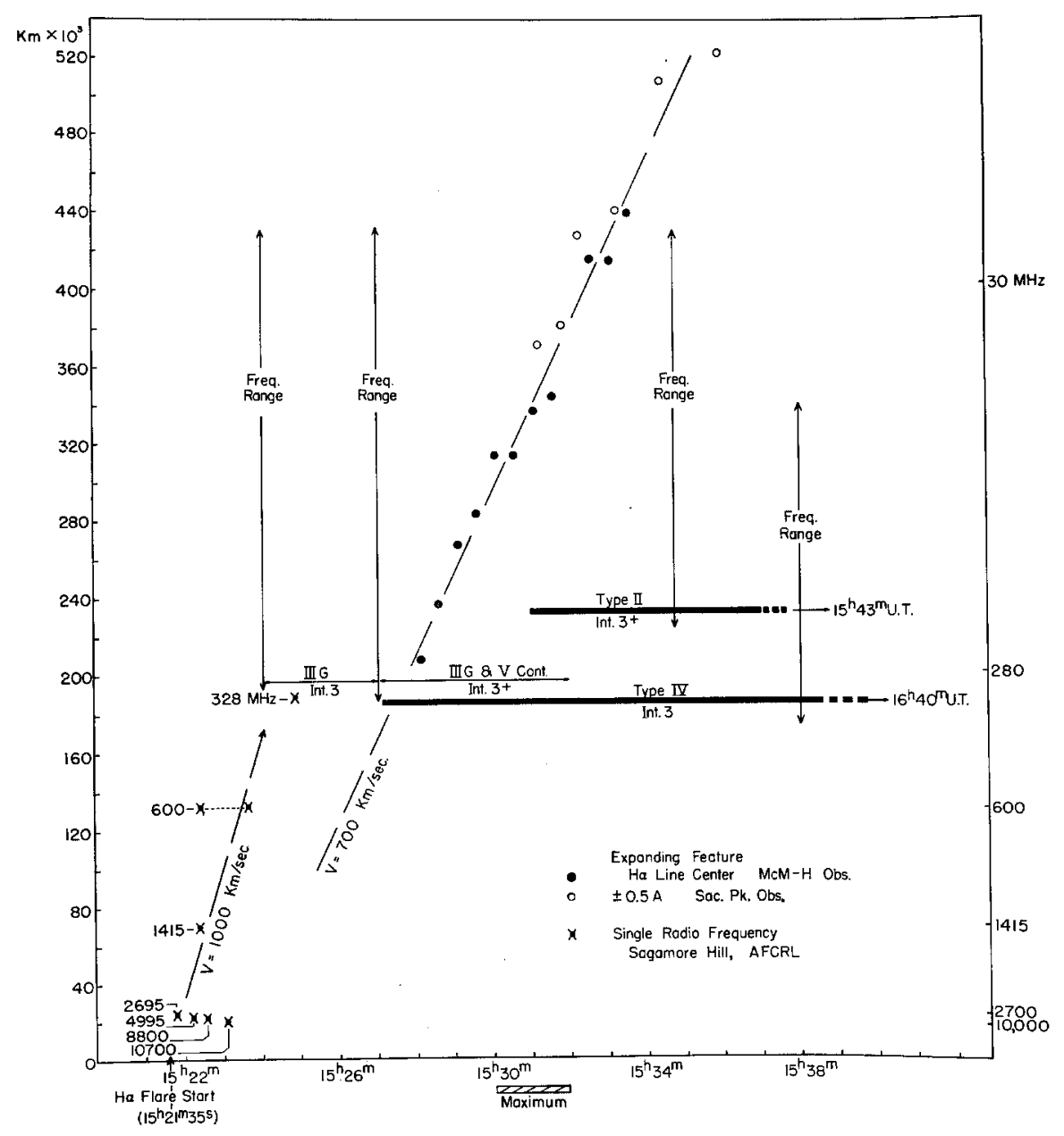

Fig. 5. Apparent distance of rapidly expanding feature from center of flare, and times* and theoretical heights of radio frequency emission, August 28, 1966.

* See footnote page 237 . 
blue side of $\mathrm{H} \alpha$, with the disturbance advancing across the solar disk with an apparent lateral velocity of the order of $600 \mathrm{~km} / \mathrm{sec}$ (DODSON and HEDEMAN, 1963). On August 28,1966 there were no filaments (prominences in projection) within the path of the rapidly expanding feature. Perhaps the transient bright and dark structures shown on the filtroheliograms betray the presence of little, prominence-like features that may make up the chromosphere.

Extrapolation backward of the plot of distance vs. time in Figure 5 suggests that the expanding arc may have originated close to the $\mathrm{H} \alpha$ flare at $\sim 15^{\mathrm{h}} 24^{\mathrm{m}} \mathrm{UT}$. This was a time when many things were happening in the flare. In $\mathrm{H} \alpha$, intensity was increasing rapidly and the regions which were to coalesce into the two bright filaments had just become conspicuous. At radio wavelengths, a group of Type-III bursts (Int. 3) at $20-350 \mathrm{MHz}$ was recorded at $15^{\mathrm{h}} 24^{\mathrm{m}} \mathrm{UT}$. Single frequency records show that enhanced emission occurred first at $\sim 10 \mathrm{~cm}$ at $15^{\mathrm{h}} 21.8^{\mathrm{m}}$, practically simultaneously with the start of the $\mathrm{H} \alpha$ flare. Seconds to minutes later, enhancements began at both shorter and longer wavelengths, and by $15^{\mathrm{h}} 24^{\mathrm{m}} \mathrm{UT}$ were in progress throughout the radio spectrum. These phenomena are shown schematically in Figure 5 where the starting times of emission at single frequencies are plotted vs. the theoretical, effective heights of the sources of the respective radiations (SHKLovsKII, 1965).

The time of onset of visibility on center-of-H $\alpha$ filtroheliograms of the transient, rapidly expanding feature, $15^{\mathrm{h}} 28^{\mathrm{m}} \mathrm{UT}$, was very close to the starting time in the radio spectrum of a second and greater group of Type-III bursts with Type-V continuum, $15^{\mathrm{h}} 27^{\mathrm{m}} \mathrm{UT}$. Figure 5 shows that the expanding $\mathrm{H} \alpha$ feature appeared just about as far from the center of the $\mathrm{H} \alpha$ flare, as the source of the concomitant radio emission is considered to have been above the photosphere. Type-IV emission also is reported by Fort Davis * as starting at $15^{\mathrm{h}} 27^{\mathrm{m}} \mathrm{UT}$ and a Type-II burst $(>150-<25 \mathrm{MHz}$ ) began at $15^{\mathrm{h}} 31^{\mathrm{m}}$, three minutes after the beginning of visibility of the expanding $\mathrm{H} \alpha$ feature. The Boulder observations (41-11 MHz) indicate a Type- $\Pi$ burst starting at $15^{\mathrm{h}} 30^{\mathrm{m}} 15^{\mathrm{s}}$ and lasting for $17 \mathrm{~min}$.

It should be recalled that velocities of $\sim 700 \mathrm{~km} / \mathrm{sec}$ have been exhibited by eruptive prominences ejected in the pre-maximum phase of certain great flares at the $\operatorname{limb}$ (Dodson et al., 1953). Such ejections probably are unobservable directly on monochromatic records made in the neighborhood of $\mathrm{H} \alpha$ because of large Doppler shifts. It is to be hoped that future observations made far from $\mathrm{H} \alpha$ will reveal the relationship of such ejections to the rapidly expanding, flare-associated features observed in and near the center of $\mathrm{H} \alpha$ as on August 28, 1966.

\section{Relation of $\mathrm{H} \alpha$. Flare-Emission to Filament Activity}

Although the $\mathrm{H} \alpha$ flare here considered did not brighten to flare-intensity according to our records until $15^{\mathrm{h}} 21^{\mathrm{m}} 35^{\mathrm{s}}$, there is evidence of activity apparently related to the flare

* The dynamic radiofrequency events here reported are in general accord with both the published and private communications from A. Maxwell. The Reports of the Fort Davis data for Aug. 28, 1966, published by C. Hyder in Solar Phys. 2, 70 and 276, were inadvertently incorrect. 
during at least an hour preceding the flash phase of emission in $\mathrm{H} \alpha$. Our photographic record begins at $13^{\mathrm{h}} 04^{\mathrm{m}} \mathrm{UT}$. At this time the plage containing the large spot group was traversed by a conspicuous, sharply defined, relatively straight dark filament. (See Figure 3a.) As early as $13^{\mathrm{h}} 38^{\mathrm{m}}$ this filament, though still well defined, began to curve Southward. Observations in the wings of $\mathrm{H} \alpha$ at $14^{\mathrm{h}} 19^{\mathrm{m}}$ indicated the presence within it of Doppler shifts both + and - . Filament activity prior to the onset of a flare is a well-observed phenomenon (SMITH and RAMSEY, 1964). It should be noted that the $18 \mathrm{MHz}$ record which had been undisturbed during earlier hours developed a 'noise storm' or series of many bursts at $13^{\mathrm{h}} 30^{\mathrm{m}} \mathrm{UT}$ and continued to be disturbed until $20^{\mathrm{h}} 15^{\mathrm{m}} \mathrm{UT}$.

At $14^{\mathrm{h}} 30^{\mathrm{m}}$ UT the filament began to lose contrast in the monochromatic pictures and to bend further towards the South. The process continued until the filament seemed to become part of a previously existing system of fine dark structures, convex Southward. The Western end of the filament disappeared by $14^{\mathrm{h}} 40^{\mathrm{m}} \mathrm{UT}$ and at $14^{\mathrm{h}} 53^{\mathrm{m}}$ UT a subflare developed near its former location. Between $15^{\mathrm{h}} 00^{\mathrm{m}} \mathrm{UT}$ and $15^{\mathrm{h}} 05^{\mathrm{m}} \mathrm{UT}$ more of the filament disappeared. At $15^{\mathrm{h}} 10^{\mathrm{m}} \mathrm{UT}$ only the extreme Eastern part of the filament could be seen as an absorption feature. It was bent far Southward. Low intensity, plage-like brightness occurred where the absorption filament had existed at $13^{\mathrm{h}} 10^{\mathrm{m}} \mathrm{UT}$. At $15^{\mathrm{h}} 15^{\mathrm{m}}$ slender bright structures were intermingled with the system of curvilinear absorption features.

The first flare-emission, regions 1 and 2 of Figure 1, developed near the Western extremity of the curvilinear system of structures described above. These flare regions also were located on either side of filament $F$, still visible but active. The third region of flare emission was located at the Eastern extremity of the system of curvilinear structures and at the Easternmost tip of the filament observed since $13^{\mathrm{h}} 04^{\mathrm{m}} \mathrm{UT}$.

The initial regions of $\mathrm{H} \alpha$ flare emission thus occurred relatively far from the strong magnetic fields of the spots and apparently close to the extremities of a feature which, if seen at the limb, possibly would have been described as the early phase of an ascending prominence. It is of interest that the early system of curvilinear structures and the active filament seem to have been oriented or directed towards the brightest parts of the expanding feature as drawn in Figure 1B. The association here described between inferred prominence activity on August 28 and the outbreak of the great flare on this date suggests strongly the need for a more detailed understanding of the relationships between fast ejections recorded at the limb in the premaximum phase of certain flares and the various aspects of flares observed near the center of the solar disk.

\section{Acknowledgement}

We are most grateful to the Sacramento Peak Observatory for having made its films of the 1966 August 28 flare available for use in the international Proton Flare Project of which this investigation is a part. It is especially gratifying when, as in this study, independent records of transient solar phenomena confirm and supplement each other. 


\section{References}

Dodson, Helen W.: 1952, Astrophys. J. 115, 320.

Dodson, Helen W. and Hedeman, E. Ruth: 1963, AAS-NASA Symposium on the Physics of Solar Flares, p. 15.

Dodson, Helen W. and Hedeman, E. Ruth: 1967, 'Some Patterns in the Development of Centers of Solar Activity, 1962-1966', in IAU Symposium No. 35 (ed. by K.O. Kiepenheuer), p. 56.

Dodson, Helen W., Hedeman, E. Ruth, and Chamberlain, J.: 1953, Astrophys. J. 117, 66.

Dodson, Helen W., Hedeman, E. Ruth, and McMath, R.R.: 1956, Astrophys. J. Suppl. Series (No. 20) 2, 241.

ShrlovskiI, I.: 1965, Physics of the Solar Corona, p. 344.

Smith, S.F. and Ramsey, H.E.: 1964, Z. Astrophys. 60, 1. 